...All too sadly we can fall into the trap

of believing that such events cannot or

will not happen to us. But they do.

\title{
Benevolence and personal tsunamis
}

It is a fair bet that many people had never even heard the word tsunami before the terrifying consequences of the recent tidal waves in the Indian Ocean.

Tragically, we are now all familiar with the word and the potential effects both physical and emotional of one of nature's deadliest of phenomena.

The response was almost as swift and overwhelming as the tragedy itself. Outpourings of cash, support, clothing, expertise and every type of help were immediately forthcoming. Even the $B D J$ received calls from dentists anxious to lend their skills if required. As reported here two issues ago, the FDI World Dental Federation (of which the BDA is a member association) has announced that it too through its World Dental Development Fund is offering aid to affected regions and organisations, although as they noted 'oral health will likely be addressed as part of the long term reconstruction phase of the disaster.'

Such charitable activity is entirely laudable and a very human reaction to such an awful circumstance, highlighted by the scale, immediacy and media attention. Essentially though, the disaster is formed of hundreds, thousands, millions of tiny disasters, personal tsunamis whose individual waves are just as devastating and whose needs are just as great. What I believe we should also think of, as a positive response to this, are the numerous examples of personal distress that occur everyday without that same scale, immediacy or media focus but with just as much personal hurt and upset.

The tendency is to think of dentists as at least reasonably well-off people, and for the most part, joking apart, it is fairly accurate. We have much about which to be thankful and grateful. But some of our colleagues and their dependents do not. The BDA Benevolent Fund (which in fact provides help to all in the profession, not just BDA members) stands to provide such help and assistance. In 2004 it gave out no less than $£ 200,000$ in grants and loans to those of our colleagues who had fallen on hard times. One third of the applications were due to accidents or illness, 45 per cent due to stress, addiction and mental health problems and a further 22 per cent as a result of poverty, marital breakdown and bereavement.

All too sadly we can fall into the trap of believing that such events cannot or will not happen to us. But they do. Doubtless every one of last year's recipients would have said the same thing had we asked the question but weeks or days before their personal tsunami broke over them. There are some rather alarming further statistics too. For example, about 30 per cent of the applications are from dentists in their 20s and 30s, and this is a rising trend. Surely something that needs addressing here and elsewhere.

But this is not simply a plea for "charity to begin at home'. We have many 'homes' and many calls on our resources. Examples abound in the raft of charities which provide essential aid overseas as well as in the UK, Dentaid is a growingly famous example, while the long-standing Cordent Trust provides an example from my experience, of another smaller yet carefully focussed organisation working for the benefit of oral health in deprived areas of the world.

Instead I believe that the awful events of the tsunami should lead us not only to compassion and action in far away places but also to give similar consideration to those nearby us every day, whether they are in direct need, potential need or are indeed already working for the needs of others. As a profession that deals in care and concern as the currency of our working days we should also spare some time, in our admittedly full and busy lives, to reflect on those less fortunate in terms of oral health and also of general, mental, physical and spiritual health. It is a sign of a grown-up profession.

Stephen Hancocks OBE, Editor-in-Chief doi:10.1038/sj.bdj.4812114 